\title{
Gynecologic Oncology Group
}

National Cancer Institute

\section{Source}

National Cancer Institute. Gynecologic Oncology Group. NCI Thesaurus. Code C25521.

A non-profit $\mathrm{NCl}$-supported org anization with the purpose of promoting excellence in the quality and integrity of clinical and basic scientific research in the field of gynecologic malignancies. Approximately 45 individual clinical trials are active at any one time within GOG. 